\title{
Improvement on The Ellis and Roberts Viability Model
}

\author{
Guoyan Zhou, Feifei Zhang, Shaoyun $\mathrm{Wu}^{\text {\#*}^{*}}$
}

Biotechnology and Germplasm Resources Institute, Yunnan Academy of Agricultural Sciences; Key Lab of Agricultural Biotechnology, Yunnan Province; Key Lab of Southwestern Crop Gene Resources and Germplasm Innovation, Ministry of Agriculture. Kunming, P.R. China A R T I C L E I N F O

\#They contribute equally to this paper

Article history:

Received 16 July 2015

Accepted 21 February 2016

Available online, ISSN: 2148-127X

Keywords:

Improvement

Seed longevity

Viability model

Storage temperature

Water content of seeds

${ }^{*}$ Corresponding Author:

E-mail: caiyunwu205cn@aliyun.com \begin{abstract}
A B S T R A C T
With data sets of germination percent and storage time of seed lot of wheat and sorghum stored at three different storage temperature $\left(t,{ }^{\circ} \mathrm{C}\right)$ with three different water content $(m$, $\%$ ) of seeds, together with data set of buckwheat and lettuce reported in literatures, the possibility that seed survival curve were transformed into line by survival proportion and the relationship that logarithm of average viability period $(\log p 50)$ and standard deviation of seed death distribution in time $(\delta$ )with $t, m$ and interaction between $t$ and $m$ were analysed. Result indicated that survival proportion transformed seed survival curve to line were much easier than the probability adopted by Ellis and Roberts, and the most important factor affecting $\log 550$ and $\delta$ of seed lot was interaction between $t$ and $m$. Thus, Ellis and Roberts viability model were suggested to be improved as $\mathrm{Ki}=\mathrm{Vi}-\mathrm{p} / 10 \mathrm{~K}-\mathrm{CWT}$ $(t \times m)$ to predict longevity of seed lot with initial germination percent unknown, a new model of $G_{i} / G_{0}=A-P / 10^{K-C}{ }_{W T}^{(t \times m)}$ was constructed to predict longevity of seed lot with initial germination percent already known.
\end{abstract}

\section{Introduction}

In addition to seed quality and the germination rate, seed moisture content and storage temperature are the important environmental factors affecting the seed vigor, which usually declined gradually with the storage time. Based on the research of the mechanism of seed vigor descent and the fact that seed longevity is predictable, three important assumptions predicting seed longevity were proposed and three basic viability equations were constructed (Roberts 1973). They are: 1) the distribution of seed survival period for individuals within populations could be described by a negative accumulative normal distribution, 2) the time range of the distribution was proportionate to the population average viability period $(\mathrm{p} 50), 3)$ the relationship between storage Temperature $\left({ }^{\circ} \mathrm{C}\right)$, seed moisture content $(\mathrm{m}, \%)$ and the logarithm value of p50 was simple negative linear as equation (Equ.1).

$\log p 50=K_{v}-C_{1 t}-C_{2 m}$

(Equ. 1)

The equation indicated that there was no interaction between storage temperature and seed moisture content that influencing seed viability Where $K v$ is a constant, $C_{l}$ and $C_{2}$ are simple regression coefficients. Based on the above assumptions and basic viability equations, an improved viability equation (Equ.2) prediction the longevity of the seeds stored in any environment is proposed (Ellis and Roberts 1980a).

$V_{i}=K_{i}-p / 10^{K_{E}-C_{w} \log m-C_{H t}-C_{Q t^{2}}}$

Where $V_{i}$ is the probability of the seed germination percent at the storage time $p(\mathrm{~d}), K_{i}$ is the intercept of the probability regression equation, $K_{E} C_{W} C_{H}$ and $C_{Q}$ are species constants. A part of the equation (Equ.2), namely equation (Equ.3) is standard deviation $(\delta)$ of the seed death distribution in time.

$\delta=10^{K_{E}-C_{W} \log m-C_{H t}-C_{Q t^{2}}}$

(Equ.3)

This prediction model (Equ.2 and 3) was widely cited (Wilson et al. 1989; Li and Shi 1991; Pieta and Ellis 1992; Niedzielski et al. 2009) and had an important and positive impact on the research of seed storage longevity. However, it suffered doubt for following restrictions (Ellis et al. 1989; Fabrizius et al. 1999; Tang et al. 1999): a) the model was only applicable within a limited temperature range, and it is not suitable for predicting longevity of seeds stored at $-20^{\circ} \mathrm{C}$ (Ellis and Roberts $1980 \mathrm{~b})$. The $\left(-C_{H} t\right)+\left(-C_{Q} t^{2}\right)$ of the model is 0 when barley seed stored at $-93.4^{\circ} \mathrm{C}$, and the seed longevity predicted would decrease rather than increase if storage temperature further declines(Ellis and Roberts 1980b). In fact, the temperature range fit for $t^{2}$ is $20^{\circ} \mathrm{C}-40^{\circ} \mathrm{C}$ (Ellis and Roberts 1981). Moreover, the interaction between storage temperature and seed moisture was not embodied in the model, which usually remarkably affected the seed 
longevity (Schroeder and Walker 1987; Yu et al. 2006; Sastry et al. 2007; Alhamdan et al. 2011). b) the model was not suitable for predicting longevity of seeds with dormancy characteristics (Ellis and Roberts 1980a) or low vigor, seeds of grasses (Ellis et al. 1989), even hybrid corn (Tang et al. 1999) and soybean (Fabrizius et al. 1999). c) the species constants of the model were just available for the most temperate species of the important agriculture crops, and it would consume tens of thousands of seeds of each species to measure it (Robert et al. 2009), which is a problem for seeds stored at low temperatures genebank with limited number. d) Different seeds lot or varieties of the same species, or identical seed lot with different pre-storage environmental conditions (planting location, climate at harvest and processing) have different $K_{i}$ values (Ellis and Roberts 1981). But taking $K_{i}$ values as the probability of the initial mass before storage (Ellis and Roberts 1980a), seed lot constants (Ellis and Roberts 1980a, 1980b; Ellis and Roberts 1981; Vertucci et al. 1994), or potential longevity of the seed lot (Ellis et al. 1993) is doubtable. Because it's considered to be the probability of germination percent of seeds at start or before storage (Ellis and Roberts 1980a), or the store time is 0 (Ellis and Roberts 1980b), it is thus not affected by the environmental conditions of storage (Filfho and Ellis 1992; Tang et al. 1999). Therefore, $K_{i}$ values of the identical seed lot with environmental conditions were same before and under storage should be the same. But significant difference of $K_{i}$ was found in common wheat seeds with same environmental conditions before and under storage, the only difference was the package type (Wu and Zhou 2011). e) the transforming of germination percent of seed after storage into a probability value facilitate the transforming of the seed survival curve into a straight line (Ellis and Roberts 1980a) and the further prediction of p50 using the regression equation of probability (Equ.4).

$V_{i}=K_{i}(1 / \delta) p$

(Equ.4)

However, systematic deviation from the transforming of germination percent into the probability usually resulted the significant or very significant $\chi^{2}$ (Wilson et al. 1989) of the equation (Equ.4), thus undermining the fitting and predictability of the equation (Equ.4).

The purpose of this paper is to modify Ellis and Roberts viability model on the basis of analysis that seeds survival curve's transforming into a straight line were feasible by survivors proportion (Walters et al. 2005), and that effect of interaction between the storage temperature and seed moisture content on the average viability period and standard deviation of seed death distribution in time were indeed significant, using data of germination percent and storage time from storage experiment.

Consideration is based on following: a) If the survival ratio containing initial germination percent derived from the germination percent of seed after storage could convert seed survival curve into a straight line like probability does, and to avoid the significant chi-square of the equation (Equ.4), then the survival ratio could replace the probability $\left(V_{i}\right)$ of the equation (Equ.2) and (Equ.3); b) if the effect of interaction between storage temperature and seed moisture content on longevity of seed during storage was significant, then the equation (Equ.2),(Equ.3) and (Equ.4) could be rewritten into the straight regression equation as the equation (Equ.5), (Equ.6) and (Equ.7), respectively, or the equation similar to them.

$G_{i} / G_{0}=A-p / 10^{K_{E}-C_{W} \log m-C_{H t}-C_{Q t^{2}}-C_{W T t} \log m}$
$G_{i} / G_{0}=A-(1 / \delta) p$
$\log \delta=K_{E}-C_{W} \log m-C_{H t}-C_{Q t^{2}}-C_{W T t} \log m$

Where $1 / \delta$ is the slope of the regression line, that is the deterioration rate of seed at storage period, $G_{i}$ is the seed germination percent in the storage time $p(\mathrm{~d}), G_{0}$ is the initial germination percent of the seeds at the storage beginning, $A$ is the intercept of the linear regression equation, $C_{W T}$ is the regression coefficients of interaction between storage temperature and seed moisture content $(t \times \log m$ or $t \times m)$.

\section{Materials and Methods}

Storage Experiment

Wild emmer

wheat

(T.turgiduum susp.dicoccoides,TTDIC), cultivated emmer wheat (T.turgiduum susp.dicoccum, TTDICO) and Oriental wheat (T.turgiduum susp.turanicum, TTUR) of Triticum turgiduum (AABB, 2n=4x=28, TT), Zhukovsky wheat (T.zhukovskyi, AAAAGG, 2n=6x=42, TZ), Chinese spring (T.aestivum subsp.aestivum cv.Chinese spring, TAECH) were introduced from the Chinese National Crop Genebank, at Institute of Crop Science of Chinese Academy of Agricultural Sciences(ICS-CAAS), and three strains (RS01, YV10141, and YV10142) of T.aestivum subsp.aestivum (AABBDD, $2 \mathrm{n}=6 \mathrm{x}=42$, TAE) were bred by Biotechnology and Germplasm Resources Institute of Yunnan Academy of Agricultural Sciences, this wheat seeds harvested in May 2010 in Kunming. Three seed lot of red sweet sorghum (RSS), high red sorghum (HRS) and sweet sorghum (SS) of sorghum bicolor were landraces in Yunnan province, their seeds were also harvested in October 2009 in Kunming.

Before the storage experiment, wheat seeds have been kept at low temperature(temperature ranged from $-10^{\circ} \mathrm{C}$ to $-5^{\circ} \mathrm{C}$ ) for five months, and sorghum seeds have been firstly kept at room temperature for seven months, and then transferred to the low temperature (temperature ranged from $-10^{\circ} \mathrm{C}$ to $-5^{\circ} \mathrm{C}$ )for five months.

Prior to the experiment, water content and germination percent of each seed lot were measured according to method of the ISTA (2011), and then was divided into three groups. The first group was then subdivided into 1015 small samples about 500 seeds in each, packed and vacuum-sealed in a thin layer of Aluminium foil bag, individually. The second group was packed in the cloth bag with its external was wet, the bag was then placed in the pallet of glass tank inner with water under the pallet, 
and the seeds were stored in the tank for three days with lid covered. Starting from the day of the storage, the seeds in the bag were stirred and external of the bag were wet two times per day, to make sure the seeds in the bag were fully and uniformly wet with higher moisture content. The third group were placed in the seed rack in a dry room with humidity of $10-25 \%$ and temperature of $30-35^{\circ} \mathrm{C}$ and dried for 15 days, to make them contain relatively low moisture content. After the wetting and drying treatment, the moisture content and germination percent of the seeds were measured again according to the ISTA (2011) and were divided into 10-15 small sample with approximately 500 seeds, were also vacuum sealed and packaged in a thin layer of aluminium platinum bag. Then, each seed lot of three different moisture content were stored in incubator of $20^{\circ} \mathrm{C}, 30^{\circ} \mathrm{C}$ and $40^{\circ} \mathrm{C}$, respectively, to form a total of nine storage environments of different temperature $\times$ seed moisture content.

Collection Data of Storage Time and Germination Percent on Seed Lot

A small sample was taken out from each storage environment at certain interval since the storage day, germination experiment of the seeds sample were performed according to ISTA (2011), germination percent and actual storage time of the seeds were also recorded. Intervals of the sampling of the small ample stored at $40^{\circ} \mathrm{C}$ were 15 days, those of seeds stored at $20^{\circ} \mathrm{C}$ and $30^{\circ} \mathrm{C}$ were 30 days, 60 days and 90 days, diversely. The longest storage time of the small sample was 810 days. The data of buckwheat (Fagopyrum escutentum) cv.Kyushu Zairai Hanadaka Saba (KZHS) and lettuce (Lactuca sativa) cv. Black seeded simpson (BSSS) were taken from the storage experiment of Yoshiaki Nishikawa (Nishikawa and Mumford 1989) and Hu (Hu et al. 2008).

\section{Statistical Analysis of Data and Figure Drawing}

Firstly, the germination percent of each seed lot at each storage environment was screened, only those with germination percent declined one probit at least are kept for following experiment. one probit are that germination percent from $97.7 \%$ down to $84.1 \%$ (Ellis et al. 1989) or $84 \%$ down to $50 \%$ (Tang et al. 1999),the storage time that corresponding with available germination percent are also available. The obtained total data sets of the seed lot of wheat, sorghum, buckwheat and lettuce were 59, 20, 5 and 22 respectively.

Then, the germination percent that observed values are $0 \%$ and $100 \%$ were converted into $0.01 \%$ and to $99.99 \%$ (Hong et al. 1999), all of the germination percent including actual observed values and after conversion were both turned into probability $\left(V_{i}\right)$ using the conversion functions Norminv function (probability, mean, standard-dev) provided by Excel 2003. The probability in the bracket of the norminv function is a ratio of number of the seed germinated and the seeds in germination test used, such as the probability is 0.5 when germination percent is $50 \%$, mean and standard-dev were taken 5 and 1. Due to the probability of germination percent of $50 \%$ was decided as 0 by Ellis and Roberts
(Ellis and Roberts 1980a), so the $V_{i}$ transformed by the norminv function not only need to subtract 5 , but also were only used to draw chart of seed survival curve. Meanwhile, the germination percent would also have been translated into survival ratio $\left(G_{i} / G_{0}\right)$. The chart of seed survival curves were drew with probability and survival ratio, by the drawing functions of Excel 2003. Regression models of linearity and probability provided by IBM SPSS v.19 were used to estimate $\delta$ and $p 50$ of equation (Equ.3 and Equ.6), logarithm of the $\delta$ and p50, that is $\log p 50$ and $\log \sigma$ were thought as the dependent variable. Therefore, stepwise regression analysis of the $\log p 50$ versus the independent variables $t, m, t \times m$ and $t \times \log m$; $\log \sigma$ versus the independent variables $t, t^{2}, m, t \times m, \log m$ and $t \times \log m$; should have been achieved, significance of the regression coefficients of the independent variables were used to determine effects of them on the dependent variable.

\section{Results}

Feasibility of Survival Ratios to Make Seed Survival Curve Transformation into Line

Seed lot of wheat: For the eight wheat seed lot or varieties with 6-7\% moisture content, their seed survival curves of probability fluctuated significantly rather than transformed into a straight line after the conversion to probability value $\left(V_{i}\right)$ whenever at the storage temperature of $20^{\circ} \mathrm{C}, 30^{\circ} \mathrm{C}$ or $40^{\circ} \mathrm{C}$ (the available data of the Chinese spring seeds stored in $40^{\circ} \mathrm{C}$ was not obtained when seeds exhausted). Although seed survival curves of survival ratios were completely consistent with the changes in the former, but its undulation degree was significantly less than the former, a linear trend was also more obvious than the former (Fig.1). Although the two survival curves of the seed lot with 10.5-11.5\% moisture content showed the similar change, but the seeds survival curves of survival ratios were almost a straight line under three temperature, while the seed survival curves of probability were a straight line only when storage temperature was $40^{\circ} \mathrm{C}$. In addition, compared with the survival curve of the seed lot with $6-7 \%$ moisture content, the oscillation extent was much smaller although there were some ups and downs both in two survival curves (Fig.1), TTUR and Chinese spring refer to T.turgiduum and T.aestivum subsp.aestivum respectively). Under two (the available data sets of the other seed lot except TTDIC and TTUR stored at $40^{\circ} \mathrm{C}$ were missing) or three (only TTDIC and TTUR) storage temperature, the two survival curves of the seed lot with $13.7-15.45 \%$ water content not only showed the same changes, but also were both the straight line at $30^{\circ} \mathrm{C}$ or $40^{\circ} \mathrm{C}$ (TTDIC and TTUR), and were also almost a straight line under $20^{\circ} \mathrm{C}$ (Fig.1), TTDIC and RS01 refers to T.turgiduum and T.aestivum subsp.aestivum respectively).

Seed lot of sorghum bicolour: There were two fast declined valleys on the probability survival curve of the sweet sorghum (SS) seeds (representing HRS and RSS, Fig.2, A) with $6.61 \%$ moisture content when it stored at $20^{\circ} \mathrm{C}$, the valleys were at the storage time of $390-480 \mathrm{~d}$ 
, and 480-660 d, respectively. When stored at $30^{\circ} \mathrm{C}$, a considerable peak with the storage time of $30 \mathrm{~d}$ showed at the storage time of $180-270 \mathrm{~d}$ on the curve, but a valley appeared at the $660 \mathrm{~d}$ on the curve. In contrast, these peaks and valleys were small at the storage time in the seed survival curve of survival ratio. The changes of two survival curve of the red sweet sorghum (RSS) seeds (representing SS and HRS, Fig.2, B) stored at $20^{\circ} \mathrm{C}$ with $11.79 \%$ moisture content are relatively flat, except at the storage time of $660 \mathrm{~d}$, and tended to be a straight line. When stored at $30^{\circ} \mathrm{C}$, the amplitude of the seed survival curve of probability was larger than the survival curve of survival ratio, especially the probability value has been lower than zero when at the storage time of $480 \mathrm{~d}$. The changes of the two survival curves was not only exactly similar, but also was almost all straight lines when stored at $40^{\circ} \mathrm{C}$. The changes of survival curve of survival ratio high red sorghum (HRS) seeds (representing SS and RSS, Fig. 2, C) stored at $20^{\circ} \mathrm{C}$ and $30^{\circ} \mathrm{C}$ with $15.35 \%$ water content were smaller than the survival curve of probability, they were both almost a straight line when stored at $30^{\circ} \mathrm{C}$.
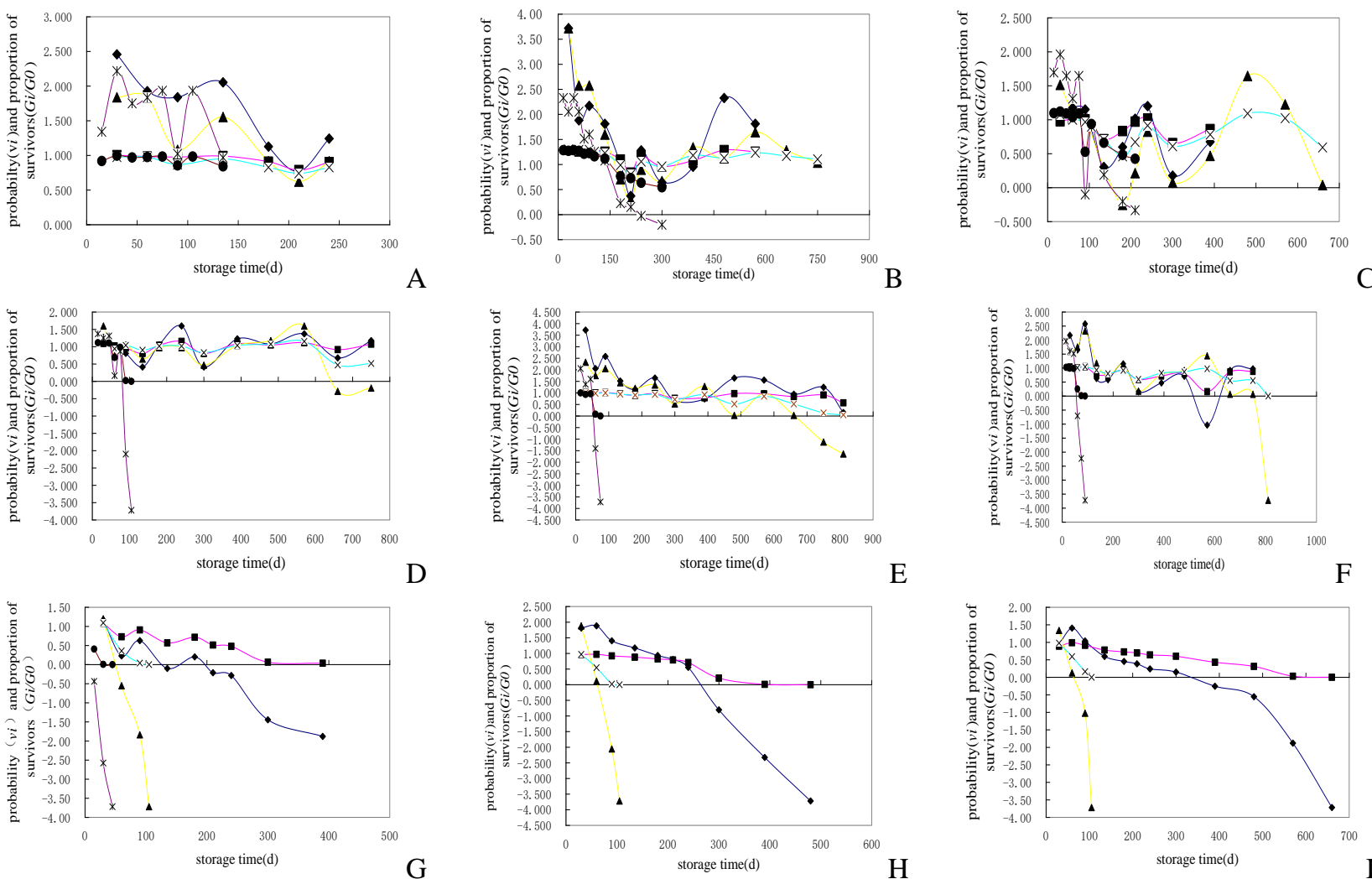

Figure 1 Survival curves of wheat seed lot stored at different temperature with different moisture content; A, T.turgiduum susp.dicoccum with $6.24 \%$ seed water content, B, T.zhukovskyi with $6.52 \%$ seed water content, C, yv10141 with $6.81 \%$ seed water content, D, T.turgiduum susp.turanicum with $10.77 \%$ seed water content, E, T.zhukovskyi with $11.49 \%$ seed water content, F, Chinese spring with $11.16 \%$ seed water content, G, T.turgiduum susp.dicoccoides with $14.79 \%$ seed water content, H, T.zhukovskyis with $13.81 \%$ seed water content, I, RS01 with $14.38 \%$ seed water content, A.D.G is survival curves of Triticum turgiduum with 6-7\%,10.5-11.5\% and 13.7-15.45\% seed water content. C.F, I is survival curves of T.aestivum subsp.aestivum with 6-7\%,10.5-11.5\% and 13.7-15.45\% seed water content stored at $20^{\circ} \mathrm{C}\left(v_{i}: \bullet, G_{i} / G_{0}: \mathbf{\bullet}\right), 30^{\circ} \mathrm{C}\left(v_{i}: \mathbf{\Delta}, G_{i} / G_{0}: \times\right)$ and $40^{\circ} \mathrm{C}\left(v_{i}:{ }^{*}, G_{i} / G_{0}: \bullet\right)$

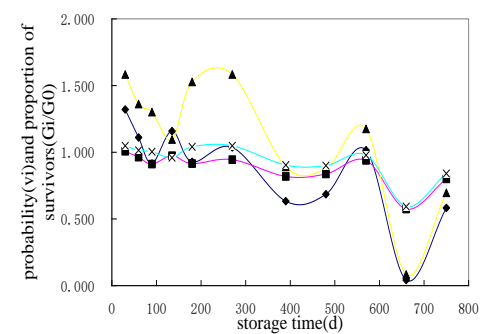

A
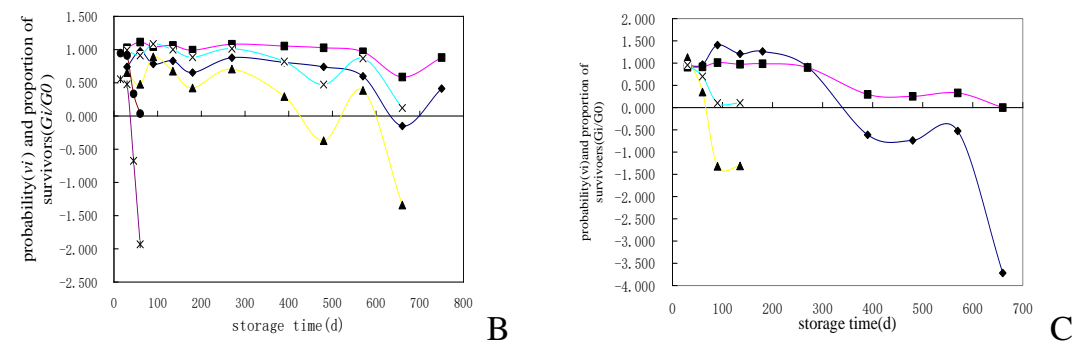

Figure 2 Seed survival curve of sorghum stored at $20^{\circ} \mathrm{C}, 30^{\circ} \mathrm{C}$ and $40^{\circ} \mathrm{C}$ with seed water content $6.61,11.79$ and $15.35 \%$; A, Seed survival curve of sweet sorghum with water content $6.61 \%$, B, red sweet sorghum stored at $20^{\circ} \mathrm{C}$, $30^{\circ} \mathrm{C}$ and $40^{\circ} \mathrm{C}\left(v_{i}: *, G_{i} / G_{0}: \bullet\right)$ with water content $11.79 \%$, C, high red sorghum with water content $15.35 \%$ stored at $20^{\circ} \mathrm{C}\left(v_{i}: \bullet, G_{i} / G_{0}: \boldsymbol{\bullet}\right)$ and $30^{\circ} \mathrm{C}\left(v_{i}: \boldsymbol{\Lambda}, G_{i} / G_{0}: \times\right)$. 


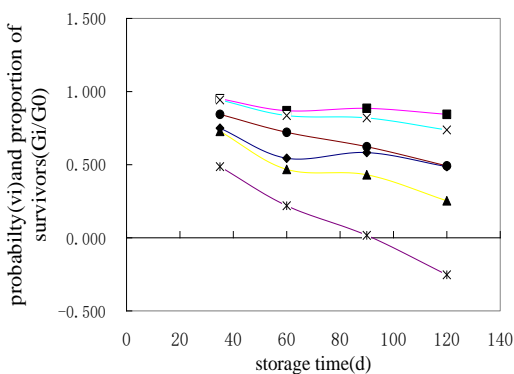

A

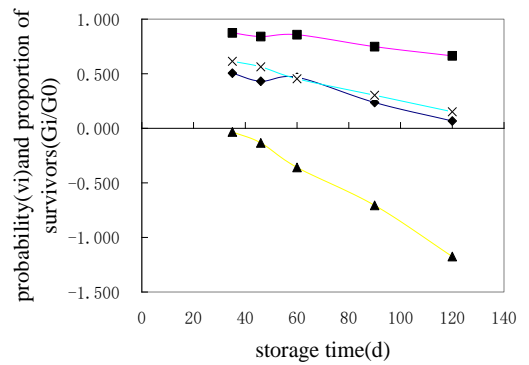

Figure 3 Seed survival curve of buckwheat; Stored at $15^{\circ} \mathrm{C}\left(v_{i}: \bullet, G_{i} / G_{0}: \boldsymbol{\bullet}\right), 25^{\circ} \mathrm{C}\left(v_{i}: \mathbf{\Delta}, G_{i} / G_{0}: \times\right)$ and $35^{\circ} \mathrm{C}\left(v_{i}: *\right.$, $\left.G_{i} / G_{0}: \bullet\right)$ with seed water content $11.98 \%(\mathrm{~A})$ and $17.89 \%(\mathrm{~B})$.
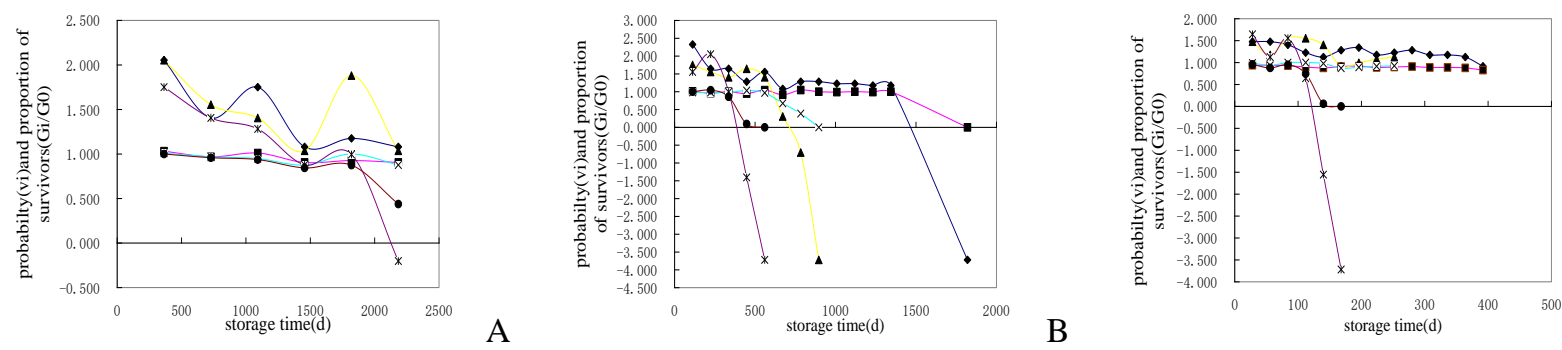

B

$\mathrm{C}$

Figure 4 Seed survival curve of Lactuca sativa seeds stored at $20^{\circ} \mathrm{C}, 35^{\circ} \mathrm{C}$ and $50^{\circ} \mathrm{C}$ with different water content; A, Seed survival curve of Lactuca sativa cv. Black seeded simpson seeds stored at $20^{\circ} \mathrm{C}$ with water content $4.8 \%\left(v_{i}: \bullet\right.$, $\left.G_{i} / G_{0}: \boldsymbol{\square}\right), 5.8 \%\left(\mathrm{vi}: \boldsymbol{\Delta}, G_{i} / G_{0}: \times\right)$ and $7.4 \%\left(v_{i}: *, G_{i} / G_{0}: \bullet\right)$, B, stored at $35^{\circ} \mathrm{C}$ with water content $5 \%\left(v_{i}: \bullet, G_{i} / G_{0}: \boldsymbol{\square}\right)$, $5.8 \%\left(v_{i}: \mathbf{\Delta}, G_{i} / G_{0}: \times\right)$ and $6.7 \%\left(v_{\mathrm{i}}: *, G_{i} / G_{0}: \bullet\right), \quad \mathrm{C}$, stored at $50^{\circ} \mathrm{C}$ with water content $4 \%\left(v_{i}: \bullet, G_{i} / G_{0}: \boldsymbol{\square}\right)$, $4.2 \%\left(v_{i}: \mathbf{\Delta}, G_{i} / G_{0}: \times\right)$ and $5.1 \%\left(v_{i}: *, G_{i} / G_{0}: \bullet\right)$.

Seed Lot of Fagopyrum Escutentum Cv.Kyushu Zairai Hanadaka Saba(KZHS)

The seed survival curves of KZHS seed lot with moisture content of $11.98 \%$ and $17.89 \%$ were both almost straight line, especially for the survival curves of survival ratio (Fig.3), whenever at the storage temperature of $15^{\circ} \mathrm{C}, 25^{\circ} \mathrm{C}$ or $35^{\circ} \mathrm{C}$.

Seed lot of Lactuca sativa cv. Black seeded simpson: The probability seed survival curves of lettuce seeds stored at $20^{\circ} \mathrm{C}$ with water content of $4.8 \%$ and $5.8 \%$ appeared the peak at the storage time of $364 \mathrm{~d}, 1092 \mathrm{~d}$ and 1820 d (Fig. 4, A), while the curve with water content of $7.4 \%$ was more gentle. However, the survival curve of survival ratio was more tending to a straight line than the seed survival curve of probability at all the moisture level. The probability survival curve of the seeds stored at $35^{\circ} \mathrm{C}$ with moisture content of $5 \%$ steadily declined at the storage time of 112-1344 d, and then became severe deterioration, although time that viability started to decline was different in the seeds with the water content of $5.8 \%$ and $6.7 \%$, the former started in the storage time of $672 \mathrm{~d}$, the latter started in the $336 \mathrm{~d}$, but the two survival curve were both tending to straight line (Fig.4, B). Seeds stored at $50^{\circ} \mathrm{C}$, no matter at what kind of water level the two survival curves were both tending to straight line, but the linearity of survival curves of survival ratio was significantly more intensity than the probability survival curves (Fig.4, C).
Therefore, no matter in what kind of storage environment (the composition of temperature and seed moisture content), the survival ratio not only can turn the seed survival curve of wheat, sorghum, buckwheat and lettuce into a straight line, but also it's better than the probability values.

Relationship between mean viability period and storage temperature, seed water content and their interaction: Since the survival ratio and the probability both can transform the seed survival curve into a straight line, then equation (6) can also be used to estimate the average viability period ( $p 50)$ of the seed stored and the standard deviation of seed death distribution in time $(\delta)$ as equation (4) did. Thus, the $p 50$ and $\delta$ of the seed lot under different storage environments were calculated through equation (4) and (6), using the data sets of germination percent and storage time of 59 wheat, 20 sorghum, 5 buckwheat and 22 lettuce from storage experiment and reported by literature. The analysis of the stepwise regression equation of the $\log 550$ and $\log \sigma$ versus the storage temperature, seed moisture content and product of both $(t \times m$ or $t \times \log m)$, the statistically significant relationship between independent variables and independent variables were detected.

Stepwise regression analysis showed that the regression equation of the $\operatorname{logp} 50$, whether the $\operatorname{logp} 50_{1}$ from equation (Equ.4) or the $\operatorname{logp} 50_{2}$ from (Equ.6), versus 
temperature $(t)$ of the seed stored, seed moisture content $(m), t \times m$ or $t \times \log m$; and constants of the equation, the coefficients of the residual independent variables not only were both statistical significance $(\mathrm{P}<0.05$ or 0.01$)$, but also all equations remained independent variable $t \times m$ or $t \times \operatorname{logm}$ (Table.1)

Accordingly, the effect of interaction between storage temperature and seed moisture content, $t \times m$ or $t \times \operatorname{logm}$, on the seed average longevity ( $p 50)$ was obvious. However, the seed lot of different species remained independent variable in the equation were different. Whether $\operatorname{logp} 50_{1}$ or $\operatorname{logp} 50_{2}$ as the dependent variable, the equation of Oriental wheat (TTUR) of Triticum turgiduum (TT) were only remained the $t \times \operatorname{logm}$; the equation of buckwheat (Fagopyrum escutentum) cv.KZHS remained $t \times m$ firstly, then introduced $t \times \log m$. when $\log 550_{1}$ as the dependent variable, the equations of Zhukovsky wheat (TZ) remained only $t \times \log m$, but there were no statistically significant variables introduced in the equation of Chinese Spring(TAECH); the equation of lettuce(BSSS) after introduced $t \mathrm{~m}$, introduced again in $t \times \log m$ and $\mathrm{m}$. But $t \times \log m$ should not be reflected in the equation KZHS and BSSS, because its coefficients $(0.036936,1.236622$ and 5.210237) made logp50 increased rather than decreased. When $\operatorname{logp} 50_{2}$ as the dependent variable, the equations of all seed lot only remained the $t \times m$, except for TTUR and KZHS.

Table 1 Stepwise regression equations and their parameters of mean vitality period versus interaction between storage temperature and seed water content.

\begin{tabular}{|c|c|c|c|c|c|c|c|c|c|c|c|c|c|c|}
\hline \multirow{3}{*}{$\begin{array}{l}\text { Name of materials } \\
\text { (Abbr.) }\end{array}$} & \multicolumn{6}{|c|}{$\operatorname{Logp} 50_{1}$} & \multirow{3}{*}{$\mathrm{IVR}^{1}$} & \multicolumn{6}{|c|}{ Logp $50_{2}$} & \multirow{3}{*}{$\mathrm{IVR}^{1}$} \\
\hline & \multicolumn{2}{|c|}{ Constant(Kv) } & \multicolumn{2}{|c|}{ Coefficient } & \multicolumn{2}{|c|}{ Equation } & & \multicolumn{2}{|c|}{ Constant (Kv) } & \multicolumn{2}{|c|}{ Coefficient } & \multicolumn{2}{|c|}{ Equation } & \\
\hline & $E^{2}$ & $\mathrm{P}$ & $E^{2}$ & $\mathrm{P}$ & $\mathrm{R}^{2}$ & $\mathrm{P}$ & & $E^{2}$ & $\mathrm{P}$ & $E^{2}$ & $\mathrm{P}$ & $\mathrm{R}^{2}$ & $\mathrm{P}$ & \\
\hline TTDIC & 4.134 & 0.003 & -0.005636 & 0.024 & 0.856 & 0.024 & $\mathrm{t} \times \mathrm{m}$ & 4.108 & 0.004 & -0.005556 & 0.029 & 0.840 & 0.029 & $\mathrm{t} \times \mathrm{m}$ \\
\hline TTUR & 3.787 & 0.000 & -0.049213 & 0.007 & 0.727 & 0.007 & $\mathrm{t} \times \log \mathrm{m}$ & 3.769 & 0.000 & -0.048733 & 0.001 & 0.844 & 0.001 & $\mathrm{t} \times \log \mathrm{m}$ \\
\hline TTDICO & 3.320 & 0.000 & -0.003557 & 0.014 & 0.664 & 0.014 & $\mathrm{t} \times \mathrm{m}$ & 3.530 & 0.000 & -0.004079 & 0.002 & 0.827 & 0.002 & $\mathrm{t} \times \mathrm{m}$ \\
\hline Combined TT & 3.385 & 0.000 & -0.003578 & 0.000 & 0.662 & 0.000 & $\mathrm{t} \times \mathrm{m}$ & 3.466 & 0.000 & -0.003764 & 0.000 & 0.761 & 0.000 & $\mathrm{t} \times \mathrm{m}$ \\
\hline $\mathrm{TZ}$ & 3.645 & 0.000 & -0.043253 & 0.026 & 0.589 & 0.026 & $\mathrm{t} \times \log \mathrm{m}$ & 3.612 & 0.000 & -0.003909 & 0.014 & 0.661 & 0.014 & $\mathrm{t} \times \mathrm{m}$ \\
\hline TAECH & & & & & & & & 3.240 & 0.000 & -0.003000 & 0.031 & 0.640 & 0.031 & $\mathrm{t} \times \mathrm{m}$ \\
\hline RS01 & 3.328 & 0.000 & -0.003133 & 0.013 & 0.606 & 0.013 & $\mathrm{t} \times \mathrm{m}$ & 3.367 & 0.000 & -0.003253 & 0.012 & 0.617 & 0.012 & $\mathrm{t} \times \mathrm{m}$ \\
\hline YV10141 & 3.740 & 0.000 & -0.004655 & 0.002 & 0.869 & 0.002 & $\mathrm{t} \times \mathrm{m}$ & 3.702 & 0.000 & -0.004520 & 0.002 & 0.877 & 0.002 & $\mathrm{t} \times \mathrm{m}$ \\
\hline YV10142 & 3.758 & 0.000 & -0.004719 & 0.004 & 0.831 & 0.004 & $\mathrm{t} \times \mathrm{m}$ & 3.775 & 0.000 & -0.004779 & 0.006 & 0.802 & 0.006 & $\mathrm{t} \times \mathrm{m}$ \\
\hline Combined TAE & 3.482 & 0.000 & -0.003766 & 0.000 & 0.698 & 0.000 & $\mathrm{t} \times \mathrm{m}$ & 3.460 & 0.000 & -0.003702 & 0.000 & 0.707 & 0.000 & $\mathrm{t} \times \mathrm{m}$ \\
\hline RSH & 4.004 & 0.000 & -0.005197 & 0.006 & 0.808 & 0.006 & $\mathrm{t} \times \mathrm{m}$ & 4.064 & 0.000 & -0.00553 & 0.008 & 0.787 & 0.008 & $\mathrm{t} \times \mathrm{m}$ \\
\hline HRS & 4.314 & 0.000 & -0.005318 & 0.005 & 0.884 & 0.005 & $\mathrm{t} \times \mathrm{m}$ & 4.586 & 0.000 & -0.005992 & 0.005 & 0.889 & 0.005 & $\mathrm{t} \times \mathrm{m}$ \\
\hline SS & 3.872 & 0.000 & -0.004633 & 0.007 & 0.796 & 0.007 & $\mathrm{t} \times \mathrm{m}$ & 3.951 & 0.000 & -0.004766 & 0.005 & 0.820 & 0.005 & $\mathrm{t} \times \mathrm{m}$ \\
\hline Combined sorghum & 4.017 & 0.000 & -0.004937 & 0.000 & 0.795 & 0.000 & $\mathrm{t} \times \mathrm{m}$ & 4.143 & 0.000 & -0.005299 & 0.000 & 0.780 & 0.000 & $\mathrm{t} \times \mathrm{m}$ \\
\hline KZHS(1) & 3.029 & 0.001 & -0.002977 & 0.025 & 0.852 & 0.025 & $\mathrm{t} \times \mathrm{m}$ & 3.107 & 0.001 & -0.003208 & 0.026 & 0.849 & 0.026 & $\mathrm{t} \times \mathrm{m}$ \\
\hline $\mathrm{KZHS}(2)$ & 2.934 & 0.000 & $\begin{array}{l}-0.005681 \\
0.036936\end{array}$ & $\begin{array}{l}0.003 \\
0.010\end{array}$ & 0.997 & 0.003 & $\begin{array}{l}t \times m \\
t \times \log m\end{array}$ & 3.004 & 0.000 & $\begin{array}{l}-0.006153 \\
0.040236\end{array}$ & $\begin{array}{l}0.002 \\
0.008\end{array}$ & 0.997 & 0.003 & $\begin{array}{l}t \times m \\
t \times \operatorname{logm}\end{array}$ \\
\hline $\operatorname{BSSS}(1)$ & 4.541 & 0.000 & -0.008762 & 0.000 & 0.768 & 0.000 & $\mathrm{t} \times \mathrm{m}$ & 5.031 & 0.000 & -0.010572 & 0.000 & 0.615 & 0.000 & $\mathrm{t} \times \mathrm{m}$ \\
\hline $\operatorname{BSSS}(2)$ & 3.857 & 0.000 & $\begin{array}{l}-0.00981 \\
1.236622\end{array}$ & $\begin{array}{l}0.000 \\
0.004\end{array}$ & 0.85 & 0.000 & $\begin{array}{l}t \times m \\
t \times \operatorname{logm}\end{array}$ & & & & & & & \\
\hline $\operatorname{BSSS}(3)$ & 3.337 & 0.000 & $\begin{array}{l}-0.010284 \\
5.210237 \\
-0.412949\end{array}$ & $\begin{array}{l}0.000 \\
0.000 \\
0.001\end{array}$ & 0.958 & 0.000 & $\begin{array}{l}\mathrm{t} \times \mathrm{m} \\
\mathrm{t} \times \log \mathrm{m} \\
\mathrm{m}\end{array}$ & & & & & & & \\
\hline
\end{tabular}

Table 2 Stepwise regression equations and their parameters of standard deviation of seed death distribution in time and interaction between storage temperature and seed water content.

\begin{tabular}{|c|c|c|c|c|c|c|c|c|c|c|c|c|c|c|}
\hline \multirow{3}{*}{$\begin{array}{l}\text { Name of materials } \\
\text { (Abbr.) }\end{array}$} & \multicolumn{6}{|c|}{$\log \delta_{1}$} & \multirow[t]{3}{*}{$\mathrm{IVR}^{1}$} & \multicolumn{6}{|c|}{$\log \delta_{2}$} & \multirow[t]{3}{*}{$\mathrm{IVR}^{1}$} \\
\hline & \multicolumn{2}{|c|}{ Constant (KE) } & \multicolumn{2}{|c|}{ Coefficient } & \multicolumn{2}{|c|}{ Equation } & & \multicolumn{2}{|c|}{ Constant (KE) } & \multicolumn{2}{|c|}{ Coefficient } & \multicolumn{2}{|c|}{ Equation } & \\
\hline & $E^{2}$ & $P$ & $E^{2}$ & $P$ & $R^{2}$ & $P$ & & $E^{2}$ & $P$ & $E^{2}$ & $P$ & $R^{2}$ & $P$ & \\
\hline TTDIC & 4.853 & 0.004 & -0.008041 & 0.018 & 0.881 & 0.018 & $\mathrm{t} \times \mathrm{m}$ & 4.925 & 0.002 & -0.006997 & 0.017 & 0.886 & 0.017 & $\mathrm{t} \times \mathrm{m}$ \\
\hline TTUR & 4.279 & 0.000 & -0.073130 & 0.003 & 0.787 & 0.003 & $\mathrm{t} \times \log \mathrm{m}$ & 4.475 & 0.000 & -0.062631 & 0.003 & 0.800 & 0.003 & $\mathrm{t} \times \log \mathrm{m}$ \\
\hline TTDICO & 3.178 & 0.000 & -0.004278 & 0.031 & 0.566 & 0.031 & $\mathrm{t} \times \mathrm{m}$ & 4.045 & 0.000 & -0.005075 & 0.004 & 0.767 & 0.004 & $\mathrm{t} \times \mathrm{m}$ \\
\hline Combined TT & 3.500 & 0.000 & -0.004756 & 0.000 & 0.615 & 0.000 & $\mathrm{t} \times \mathrm{m}$ & 4.025 & 0.000 & -0.004685 & 0.000 & 0.730 & 0.000 & $\mathrm{t} \times \mathrm{m}$ \\
\hline $\mathrm{TZ}$ & 3.261 & 0.000 & -0.004339 & 0.023 & 0.603 & 0.023 & $\mathrm{t} \times \mathrm{m}$ & 4.246 & 0.000 & -0.057259 & 0.018 & 0.633 & 0.018 & $\mathrm{t} \times \log \mathrm{m}$ \\
\hline TAECH & & & & & & & & 3.508 & 0.000 & -0.003353 & 0.042 & 0.598 & 0.042 & $\mathrm{t} \times \mathrm{m}$ \\
\hline RS01 & 3.465 & 0.000 & -0.004342 & 0.010 & 0.634 & 0.010 & $\mathrm{t} \times \mathrm{m}$ & 3.848 & 0.000 & -0.003998 & 0.012 & 0.617 & 0.012 & $\mathrm{t} \times \mathrm{m}$ \\
\hline YV10141 & 4.215 & 0.000 & -0.006922 & 0.004 & 0.834 & 0.004 & $\mathrm{t} \times \mathrm{m}$ & 4.393 & 0.000 & -0.005922 & 0.006 & 0.809 & 0.006 & $\mathrm{t} \times \mathrm{m}$ \\
\hline Y10142 & 4.039 & 0.000 & -0.006405 & 0.006 & 0.810 & 0.006 & $\mathrm{t} \times \mathrm{m}$ & 4.250 & 0.000 & -0.005544 & 0.008 & 0.788 & 0.008 & $\mathrm{t} \times \mathrm{m}$ \\
\hline Combined TAE & 3.568 & 0.000 & -0.004968 & 0.000 & 0.661 & 0.000 & $\mathrm{t} \times \mathrm{m}$ & 3.921 & 0.000 & -0.004457 & 0.000 & 0.676 & 0.000 & $\mathrm{t} \times \mathrm{m}$ \\
\hline RSS & 4.096 & 0.000 & -0.005514 & 0.006 & 0.801 & 0.006 & $\mathrm{t} \times \mathrm{m}$ & 4.273 & 0.000 & -0.004877 & 0.008 & 0.786 & 0.008 & $\mathrm{t} \times \mathrm{m}$ \\
\hline HRS & 4.194 & 0.000 & -0.005627 & 0.008 & 0.861 & 0.008 & $\mathrm{t} \times \mathrm{m}$ & 4.953 & 0.000 & -0.006263 & 0.004 & 0.894 & 0.004 & $\mathrm{t} \times \mathrm{m}$ \\
\hline SS & 3.830 & 0.000 & -0.004939 & 0.009 & 0.771 & 0.009 & $\mathrm{t} \times \mathrm{m}$ & 4.333 & 0.000 & -0.005002 & 0.006 & 0.813 & 0.006 & $\mathrm{t} \times \mathrm{m}$ \\
\hline Combined sorghum & 4.014 & 0.000 & -0.005300 & 0.000 & 0.802 & 0.000 & $\mathrm{t} \times \mathrm{m}$ & 4.467 & 0.000 & -0.005259 & 0.000 & 0.802 & 0.000 & $\mathrm{t} \times \mathrm{m}$ \\
\hline KZHS(l) & 2.996 & 0.000 & -0.002385 & 0.005 & 0.948 & 0.005 & $\mathrm{t} \times \mathrm{m}$ & 3.364 & 0.000 & -0.002431 & 0.006 & 0.941 & 0.006 & $\mathrm{t} \times \mathrm{m}$ \\
\hline $\mathrm{KZHS}(2)$ & 3.221 & 0.000 & -0.002221 & 0.002 & 0.997 & 0.003 & $\mathrm{t} \times \mathrm{m}$ & & & & & & & \\
\hline & & & -0.019396 & 0.030 & & & $\mathrm{~m}$ & & & & & & & \\
\hline BSSS & 4.526 & 0.000 & -0.010833 & 0.000 & 0.800 & 0.000 & $\mathrm{t} \times \mathrm{m}$ & 5.497 & 0.000 & -0.012098 & 0.000 & 0.649 & 0.000 & $\mathrm{t} \times \mathrm{m}$ \\
\hline
\end{tabular}

${ }^{1}$ IVR: Independent variable remained; ${ }^{2} \mathrm{E}$ : Estimate; Where $P$ is significant level and $R^{2}$ is determination coefficient. 
Table 3 Germination percentage (GP,\%) and storage time (ST, d) of common wheat seeds stored at low temperature genebank by equation (Equ.10) and (equ.11) predicted.

\begin{tabular}{|c|c|c|c|c|c|c|c|c|c|c|c|}
\hline \multirow{3}{*}{ Code } & \multirow{3}{*}{$\mathrm{M}(\%)$} & \multirow{3}{*}{$\operatorname{IGP}(\%)$} & \multirow{2}{*}{\multicolumn{2}{|c|}{ Observed value }} & \multicolumn{3}{|c|}{ Equation (10) } & \multicolumn{3}{|c|}{ Equation(11) } & \multirow{3}{*}{ Packages } \\
\hline & & & & & \multirow{2}{*}{$\mathrm{Ki}$} & \multicolumn{2}{|c|}{ Predicted value } & \multirow{2}{*}{ A } & \multicolumn{2}{|c|}{ Predicted value } & \\
\hline & & & $\mathrm{GP}(\%)$ & $\mathrm{ST}(\mathrm{d})$ & & $\mathrm{ST}(\mathrm{d})$ & $\mathrm{GP}(\%)$ & & $\mathrm{ST}(\mathrm{d})$ & $\mathrm{GP}(\%)$ & \\
\hline \multirow[t]{2}{*}{835} & 12.4 & 90 & 76 & 2920 & 1.3824 & 3613.2 & $79.8 \mathrm{a}$ & 1.034 & 2201.8 & $71.6 \mathrm{a}$ & $\mathrm{N}$ \\
\hline & 11.9 & 90 & 88 & 3650 & 2.5375 & 7174.6 & 96.7 & 1.254 & $3158.9 \mathrm{a}$ & $85.5 \mathrm{a}$ & V \\
\hline \multirow[t]{2}{*}{839} & 12.7 & 90 & 77 & 3285 & 1.6541 & 4935.1 & 85.2 & 1.104 & 2906.8 & $75.4 \mathrm{a}$ & $\mathrm{N}$ \\
\hline & 12.4 & 90 & 73 & 4015 & 1.4466 & 4456.3 & $75.5 \mathrm{a}$ & 1.078 & 3091.8 & $67.4 \mathrm{a}$ & V \\
\hline \multirow[t]{2}{*}{842} & 12.7 & 100 & 84 & 4015 & 1.6572 & 3573.5 & $81.9 \mathrm{a}$ & 0.959 & 1393.6 & 63.3 & $\mathrm{~N}$ \\
\hline & 12.4 & 100 & 80 & 4015 & 2.5770 & 9274.6 & 96.6 & 1.081 & 3263.3 & $75.2 \mathrm{a}$ & V \\
\hline \multirow[t]{2}{*}{843} & 13 & 85 & 55 & 4015 & 1.1717 & 5691.2 & 67.8 & 1.183 & 6316.7 & 73.1 & $\mathrm{~N}$ \\
\hline & 12.6 & 85 & 57 & 4015 & 1.4523 & 6859.6 & 76.0 & 1.054 & 4473.2 & $61.8 \mathrm{a}$ & V \\
\hline 849 & 12.5 & 91 & 70 & 3650 & 1.3089 & 4205.5 & $73.5 \mathrm{a}$ & 1.005 & 2743.7 & $64.3 \mathrm{a}$ & $\mathrm{N}$ \\
\hline 851 & 12.8 & 85 & 70 & 4015 & 1.7663 & 6716.4 & 84.7 & 1.158 & $3916.4 a$ & $70.8 \mathrm{a}$ & $\mathrm{N}$ \\
\hline 853 & 12.5 & 85 & 78 & 4015 & 1.5846 & 4354.7 & $79.8 \mathrm{a}$ & 1.119 & 2338.1 & 67.2 & $\mathrm{~N}$ \\
\hline 864 & 13.3 & 85 & 86 & 3650 & 2.6471 & 8600.4 & 97.6 & 1.24 & 2713.2 & $80.7 \mathrm{a}$ & $\mathrm{N}$ \\
\hline \multirow[t]{2}{*}{865} & 12.8 & 89 & 56 & 2555 & 0.6407 & $2648.7 \mathrm{a}$ & $56.7 \mathrm{a}$ & 0.841 & $2477.5 \mathrm{a}$ & $56.4 \mathrm{a}$ & $\mathrm{N}$ \\
\hline & 11.9 & 89 & 45 & 2190 & 0.2797 & $2134.4 \mathrm{a}$ & $44.6 \mathrm{a}$ & 0.687 & 2074.9a & $44.9 \mathrm{a}$ & V \\
\hline 870 & 12.3 & 93 & 80 & 4015 & 2.8767 & 10844.5 & 98.3 & 1.122 & 3024.3 & $73.6 \mathrm{a}$ & $\mathrm{N}$ \\
\hline 874 & 12.4 & 93 & 83 & 3650 & 1.5270 & 3061.5 & $80.0 \mathrm{a}$ & 1.100 & 2400.7 & 74.4 & $\mathrm{~N}$ \\
\hline 877 & 12.4 & 62 & 50 & 4015 & 0.7112 & $3801.1 \mathrm{a}$ & $48.4 \mathrm{a}$ & 1.235 & 4966.8 & 56.2 & $\mathrm{~N}$ \\
\hline \multirow[t]{2}{*}{882} & 12.5 & 87 & 82 & 4015 & 1.5342 & 3317.1 & $78.4 \mathrm{a}$ & 1.085 & 1661.1 & 65.9 & $\mathrm{~N}$ \\
\hline & 11.9 & 87 & 80 & 4015 & 2.2047 & 7177.7 & 95.0 & 1.217 & 3401.9 & $76.8 \mathrm{a}$ & V \\
\hline \multirow[t]{2}{*}{883} & 12.6 & 85 & 80 & 3285 & 1.5899 & 4022.8 & $83.6 \mathrm{a}$ & 1.133 & 2237.1 & $73.6 \mathrm{a}$ & $\mathrm{N}$ \\
\hline & 12.4 & 85 & 78 & 3650 & 2.0160 & 6647.6 & 90.8 & 1.279 & 4190.8 & $83.3 \mathrm{a}$ & V \\
\hline 886 & 12.9 & 96 & 78 & 4015 & 1.7821 & 5478.2 & 85.2 & 1.012 & 2344.4 & 66 & $\mathrm{~N}$ \\
\hline 887 & 12.4 & 88 & 74 & 3650 & 1.7405 & 5863.9 & $85.5 \mathrm{a}$ & 1.119 & 3223.7 & $72.1 \mathrm{a}$ & $\mathrm{N}$ \\
\hline 889 & 12.6 & 89 & 85 & 3650 & 2.0815 & 5618.7 & $92 a$ & 1.168 & 2483.4 & $77.5 \mathrm{a}$ & $\mathrm{N}$ \\
\hline \multirow[t]{2}{*}{890} & 12.7 & 86 & 74 & 3650 & 2.4368 & 9670.7 & 96.1 & 1.275 & 4844.5 & 84.2 & $\mathrm{~N}$ \\
\hline & 11.7 & 86 & 70 & 4015 & 3.3550 & 14816.8 & 99.5 & 1.369 & 6313.9 & 88.8 & V \\
\hline \multirow[t]{2}{*}{892} & 12.7 & 85 & 60 & 4015 & 1.5098 & 6775.5 & 77.8 & 1.128 & 4937.8 & 68.2 & $\mathrm{~N}$ \\
\hline & 11.9 & 85 & 84 & 4015 & 2.2037 & 6367.7 & 92.5 & 1.261 & 3115.6 & $78.7 \mathrm{a}$ & V \\
\hline 895 & 12.8 & 94 & 78 & 3650 & 2.0921 & 7138.7 & 92.2 & 1.085 & 2993.3 & $74.2 \mathrm{a}$ & $\mathrm{N}$ \\
\hline & 12.1 & 94 & 68 & 4015 & 3.4406 & 15747.7 & 99.7 & 1.292 & 6538 & 90.2 & V \\
\hline 896 & 12.9 & 92 & 70 & 4015 & 1.9146 & 7541.3 & 88.0 & 1.081 & $3757.4 \mathrm{a}$ & $69.6 \mathrm{a}$ & $\mathrm{N}$ \\
\hline & 12 & 92 & 78 & 4015 & 2.7034 & 10199.7 & 97.4 & 1.216 & $4221.6 a$ & $81.2 \mathrm{a}$ & V \\
\hline 897 & 12.5 & 85 & 70 & 4015 & 1.2705 & $3999.4 a$ & $69.9 a$ & 1.073 & 2903.2 & $63.3 \mathrm{a}$ & $\mathrm{N}$ \\
\hline 898 & 12.8 & 89 & 75 & 4015 & 2.1631 & 8050.9 & 92.2 & 1.153 & $3632.3 \mathrm{a}$ & $73.7 \mathrm{a}$ & $\mathrm{N}$ \\
\hline & 12 & 89 & 84 & 4015 & 4.1818 & 16833.8 & 99.9 & 1.287 & $3941.1 \mathrm{a}$ & $84.9 \mathrm{a}$ & V \\
\hline 901 & 13 & 71 & 85 & 3650 & 1.9144 & 4776.7 & $89.3 a$ & 1.438 & 2841.6 & $81.3 \mathrm{a}$ & $\mathrm{N}$ \\
\hline 924 & 12.7 & 85 & 80 & 2920 & 1.4704 & 3390.4 & $82.4 \mathrm{a}$ & 1.117 & 2056.5 & 74.8 & $\mathrm{~N}$ \\
\hline 925 & 12.8 & 89 & 83 & 2920 & 1.9736 & 5513.5 & 92.4 & 1.144 & 2479.5 & $80.8 \mathrm{a}$ & $\mathrm{N}$ \\
\hline & 12 & 89 & 82 & 4015 & 1.7760 & 4545.2 & $84.5 \mathrm{a}$ & 1.117 & 2246.3 & 69.8 & V \\
\hline 926 & 12.7 & 91 & 40 & 4015 & 2.4194 & 14412.3 & 95.3 & 1.177 & 8614.2 & 77.4 & $\mathrm{~N}$ \\
\hline 933 & 12.7 & 96 & 70 & 4015 & 1.7816 & 6779.0 & 85.0 & 1.017 & $3366.1 \mathrm{a}$ & $66.3 \mathrm{a}$ & $\mathrm{N}$ \\
\hline & 12 & 96 & 68 & 4015 & 4.1596 & 19498.5 & 99.9 & 1.243 & 6128.6 & 87.3 & V \\
\hline 936 & 12.9 & 94 & 70 & 4015 & 2.2669 & 9452.0 & 93.6 & 1.085 & 3994.8 & $71.5 \mathrm{a}$ & $\mathrm{N}$ \\
\hline
\end{tabular}

IGP: Initial germination percent; a: Showed the value predicted was in the range of "observed \pm observed $\times 10 \%$; N and V: Showed no-vacuum and vacuum packages, respectively.

In stepwise regression analysis, independent variables that affected the dependent variables most was firstly introduced into regression equations, then follows minor dependent variables. So the impact of the $t \times \log m$ in the equation of TTUR introduced and in the equation of TZ introduced when $\operatorname{logp} 50_{1}$ was as the dependent variable on $p 50$ should be bigger than $t \times m$.

If $t \times \log m$ was not considered as the independent variable, the regression equation of TTUR and TZ should also remain independent variable $t \times m$. Therefore, $t \times m$, interaction between storage temperature and moisture content of seed was the major factor affecting the mean viability period for all seed lot list in Table 1 and the combination of Triticum turgiduum, T.aestivum subsp.aestivum and Sorghum bicolor seed lot combined for calculation, the negative linear relationship between average longevity and storage temperature, and seed moisture content, namely the equation (1) should be thus modified to equation (Equ.8). $\log p 50=K_{V}-C_{t m} t m$

(Equ.8)

Where $K v$ and $C_{t m}$ were the constants and the coefficients of $t \times m$ listed in Table 1 .

Relationship between Standard Deviation of Seed Death Distribution in Time and Storage Temperature, Seed water Content and their Interaction: For $\log \delta$ and the independent variables $t, t^{2}, m, t \times m, \log m$ and $t \times \log m$ of all seed lot and combination of Triticum turgiduum, T.aestivum subsp.aestivum and Sorghum bicolor seed lot, the stepwise regression analysis showed that the regression equation of TTUR only remained $t \times \log m$ (Table 2) for either $\log \sigma_{1}$ from equation (Equ.4) or $\log \sigma_{2}$ from (Equ.6), .when $\log \sigma_{1}$ was the dependent variable, the equations of all seed lot or combinations of seed lot combined for calculation only contained $t \times m$, except that no statistically significant independent variable were 
introduced into the equation of TAECH and the $m$ was introduced into the equation of KZHS after the $t \times m$; while $\log \sigma_{2}$ was the dependent variable, the equations of all seed lot or combinations of seed lot combined for calculation were also remained the $t \times m$, except that the equation of TZ retained $t \times \log m$. Although the variables remained in the equations of different seed lot were different among species, but the equations and their constants and the coefficients of independent variables were both statistically significant $(\mathrm{P}<0.05$ or 0.01$)$. Therefore, $t \times m$, the interaction between storage temperature and seed moisture content, was the most important factor affecting the standard deviation of the seed death distribution in time. Therefore, the relationship between the logarithmic of standard deviation of seed death distribution in time and interaction between the storage temperature and seed moisture content (Equ.7) should be modified to equation 9 (Equ.9).

$\log \delta=K-C_{W T} t m$

(Equ.9)

Where $K$ and $C_{W T}$ were equal to the constant $\left(K_{E}\right)$ and the coefficients of $t \times m$ listed in Table 2 .

\section{Discussion}

Improvement on the Ellis-Roberts Model and Setting up New Model

Based on the above findings and equation (Equ.9), it is recommended to modify the equation (Equ.2) reported by Ellis-Roberts (Ellis and Roberts 1980a) to the equation(Equ.10), and modify the equation (Equ.5) to the equation (Equ.11), this is a new model for prediction longevity and viability of seed with germination percent as base rather than probability.

$V_{i}=K_{i}-p / 10^{K-C_{W T} t m}$

(Equ.10)

$G_{i} / G_{0}=A-p / 10^{K-C_{W T} t m}$

(Equ.11, new model)

The equation (Equ.10) is maybe applicable to predict longevity of seed that initial seed germination percent was not determined before storage. Compared with the previous research (Schroeder and Walker 1987; Yu et al. 2006; Sastry et al. 2007; Alhamdan et al. 2011) that the effect of the interaction between storage temperature and seed content on seed longevity was significant, the study not only revealed that influence of the interaction on storage longevity of wheat, sorghum, buckwheat and lettuce seed lot were significant, but also modeled it to be used for predictive models of seed longevity.

\section{Validity of the New Model}

The validity of Equ. 10 and Equ. 11 in predicting storage temperature and germination percent was compared, using the data sets of 43 common wheat seeds samples stored at $-2^{\circ} \mathrm{C} \pm 2^{\circ} \mathrm{C}$ low temperature with germination percent have declined one probit at least and seed moisture content were determined (Zhou et al. 2011; Wu and Zhou 2011).

First, $K_{i}$ and $A$ values were estimated by the equation
(4) and (6) for each sample in Table 3, and $K$ (i.e. $\left.K_{E}\right)=3.568$ and 3.921 and $C_{W T}=0.00496$ and 0.004457 of common wheat listed in Table 2 were used, and the storage temperature $(t)$ of $-2.6^{\circ} \mathrm{C}$ was decided according to storage temperature was $2.6^{\circ} \mathrm{C}$ in fluctuating temperature range of $0-5^{\circ} \mathrm{C}$ (Ellis 1988), because of the data from the seeds stored at low-temperature genebank of $-2^{\circ} \mathrm{C} \pm 2{ }^{\circ} \mathrm{C}$. Germination percent and storage time of the seed that the equation (Equ.10) and (Equ.11) can predict were estimated and compared with actual observed value respectively using the data. When predict storage time of the seed with actual germination percent, the storage time were in 2134.4-19498.5 $\mathrm{d}$ by the equation (Equ.10) predicted, discrepancy was -697.9-15483.5 d with actual observed value. Among them, there were only 4 value predicted in the range of "observed values \pm observed values $\times 10 \%$ " (Table.3, marked "a"). The storage time were in 1393-8614 d by equation (Equ.11) predicted, discrepancy was -2621.4-4599.2 d, there were 8 values predicted in the range of "observed values \pm observed values $\times 10 \%$ (Table.3, marked "a"). When predict viability of the seed with actual storage time, the values were in $44.6-99.9 \%$ by equation (Equ.10) predicted, difference was $-3.6-55.3 \%$ with actual observed value, there were 8 values predicted in the range of "observed value \pm observed value $\times 10 \%$ " (Table. 3 , marked " $b$ "); the viability were in $44.9-90.2 \%$, difference was $-20.7-37.4 \%$ with actual observed values, there were 28 values predicted in the range of "observed values \pm observed values $\times 10 \%$ " was $65 \%$ of total of the prediction values, Obviously, veracity that equation (Equ.11) have predicted germination percent and storage time of seed were 2 and 3.5 times of the equation (Equ.10). Therefore, veracity of the survival ratio linear regression equation (Equ.11) was higher than the probability regression equation (Equ.10), with predict storage time or germination percent.

Comparing with the improved Ellis and Roberts vitality model, the new model not only avoided the problem that fitting of the equation(Equ.4) was very poor, which was caused by large $\chi^{2}$ from systematic deviation generated when germination percent were transformed into probability, but also considered an important factor that initial germination percent was initial seed quality in the traditional sense (Niedzielski et al. 2009), so that it could not only predict longevity of seed that initial germination percent was higher, such as $97.7 \%$ improved viability equation required, and could also estimate longevity of seed that initial germination percent was lower, such as $62 \%$ of 877 in Table 3.

\section{Use of the New Model}

The use of the new model is as simple as equation (Equ.2), at least three data sets of germination percent of a seed lot or variety in a stable storage condition were needed. A certain interval, by a part of the new model, namely equation (Equ.6), intercept $(A)$ and deterioration rate $(1 / \delta)$ of the seed lot were easily estimated, and then by the $A$ and $1 / \delta$ estimated predict the storage time (p,d) that germination percent of the seed lot decrease to any level under the same storage condition, or the germination 
percent at any storage time. However, different from the equation (Equ.2) or (Equ.4), the prerequisite to predict the longevity or viability of seed using equation (Equ.6) or (11) is that the germination percent of the seed lot before stored (initial germination percent) must be known. Same as equation (Equ.2), to predict longevity of seed using values of $K$ and $C_{W T}$, the germination percent and storage time data of certain seed lot in some species must be obtained under a stable storage temperature with two levels at least of seed moisture content or two stable storage temperature with a moisture content of seed at least, and the $K$ and $C_{W T}$ was calculated by combination of the equation (Equ.6) and (Equ.9), then use $K, C_{W T}$ and the equation (Equ.11) to predict longevity of the others seed lot in the same species again. We wish that the new model could be used to predict longevity of seed lot of other species except the species mentioned in this article. However, it need further investigation on whether the $K$ and $C_{W T}$ of the new model are species constants as $K_{E}$, $C_{W}, C_{H}$ and $C_{Q}$ of improved viability equation.

\section{Acknowledgements}

We would like to devote our appreciate to Professor lihua Wang from Yunnan

Academy of Agricultural Sciences (YAAS) for providing the crop seeds. We were also grateful of the financial support of YAAS.

\section{References}

Alhamdan AM, Alsadon AA, Khalil SO, Wahb-Allah MA, Nagar ME, Ibrahim AA. 2011. Influence of storage conditions on seed quality and longevity of four vegetable crops. AmericanEurasian Journal of Agriculture and Environmental Science, 11, 353-359.

Ellis RH. 1988. The viability equation, seed viability nomographs, and practical advice on seed storage. Seed Science and Technology, 16: 29-50.

Ellis RH, Roberts EH. 1980a. Improved equations for the prediction of seed longevity. Annals of Botany, 45: 13-30.

Ellis RH, Roberts EH. 1980b. The influence of temperature and moisture on seed viability period in barley (Hordeum distichum L.). Annals of Botany, 45: 31-37.

Ellis RH, Roberts EH. 1981. The quantification of aging and survival in orthodox seeds. Seed Science and Technology, 9: 373-409.

Ellis RH, Hong TD, Roberts EH. 1989. A comparison of the lowmoisture-content limit to the logarithmic relation between seed moisture and longevity in twelve species. Annals of Botany, 63 601-611.

Ellis RH, Hong TD, Jackson MT. 1993. Seed production environment, time of harvest, and the potential longevity of seeds of three cultivars of rice (Oryza sativa L.). Annals of Botany, 72: 583-590.
Fabrizius E, Tekrony D, Egli DB, Rucker M. 1999. Evaluation of a viability model for predicting soybean seed germination during warehouse storage. Crop Science, 39: 194-201.

Filfho CP, Ellis RH. 1992. Estimating the value of the seed lot constant $\left(\mathrm{K}_{\mathrm{i}}\right)$ of the seed viability equation in barley and wheat. Seed Science and Technology, 20: 93-99.

Hong TD, Ellis RH, Buitink J, Walters C, Hoekstr AFA, Crane J. 1999. A model of the effect of temperature and moisture on pollen longevity in air-dry storage environments. Annals of Botany, 83: 167-173.

Hu XR, Tao M, Lu XX, Xin PP, Chen SP, Zhou HL. 2008. Studies on optimal moisture content and longevity of lettuce seed stored at different temperatures. Acta Agriculture Jiangxi, 20: 1-5.

Li KL, Shi J. 1991. Predicting on the seed storage life expectancy of Pinus sylvestris var.mongolica and P.tabulaeformis. Journal of Northeast forestry University, 19: 24-33.

Nishikawa Y, Mumford PM. 1989. Longevity of buckwheat seeds and their tolerance to desiccation. Fagopyrum, 9: 4-9.

Niedzielski M, Walters C, Luczak W, Hill LM, Wheeler LJ, Puchalski J. 2009. Assessment of variation in seed longevity within rye, wheat and the intergeneric hybrid triticale. Seed Science Research, 19: 213-224.

Robert RJ, Daws MI, Hay FR. 2009. Ecological correlates of ex situ seed longevity a comparative study on 195 species. Annals of Botany, 104: 57-69.

Roberts EH. 1973.Predicting the storage life of seeds. Science and Technology, $1: 499-514$.

Sastry D, Upadhyaya HD, Gowda CLL. 2007. Survival of groundnut seeds under different storage conditions. Semi-AridTropics ejournal, 5: 1-3.

Schroeder WR, Walker DS. 1987. Effects of Moisture Content and Storage Temperatures on Germination of Quercus macrocarpa Acorns, Journal Environmental Horticulture, 5: 22-24.

Tang S, TeKrony DM, Egli DB, Cornelius PL, Rucker M. 1999. Survival Characteristics of corn seed during storage: I. Normal distribution of seed survival. Crop Science, 39: 1394-1400.

Tang S, TeKrony DM, Egli DB, Cornelius PL. 1999. Survival characteristics of corn seed during storage: II. Rate of seed deterioration. Crop Science, 39: 1400-1406.

Vertucci CW, Roos EE, Crane J. 1994. Theoretical basis of protocols for seed storage III. Optimum moisture contents for pea seeds stored at different temperatures. Annals of Botany, 74: 531-540.

Walters C, Hill LM, Wheele LJ. 2005. Dying while Dry: Kinetics and mechanisms of deterioration in desiccated organisms. (Oxford Journals) Integrative and Comparative Biology, 45: 751-758.

Wilson DO Jr, McDonald MB Jr, Martin St SK. 1989. A probit planes method for analyzing seed deterioration data. Crop Science, 29: 471-476.

WU SY, ZHOU GY. 2011.Comparison of aging characteristics and longevity of wheat seeds in vacuum and non-vacuum packages storage in mid-term low-temperature genebank. Acta Agronomica Sinica, 37: 09-1115.

Yu FY, Shao L, Shen YB. 2006.Studies on physiological and biochemical changes of Chinese Fir and Masson Pine Seeds during storage. Scientia Silvae Sinicae, 42: 137-142.

Zhou GY, Wu SY, Xu L. 2011.Influence of vacuum and nonvacuum packing on the viability of wheat seed stored in low temperature. Journal of Plant Genetic Resources, 12: 368-373.. 